\title{
Trend Analysis of Annual and Monthly Rainfall in Erbil City, Kurdistan Region, Iraq
}

\author{
Saud A. Hussien', Basil Y. Mustafa ${ }^{2 *}$, Farzand K. A. Medhat ${ }^{3}$ \\ ${ }^{1}$ Department of Road Construction, Erbil Technology Institute, Erbil, Erbil Polytechnic University, Kurdistan Region, Iraq, ${ }^{2}$ Department of \\ Civil Engineering, Erbil Technical Engineering College, Erbil Polytechnic University, Erbil, Kurdistan Region, Iraq, ${ }^{3}$ Department of Road \\ Construction, Erbil Technology Institute, Erbil Polytechnic University, Erbil, Kurdistan Region, Iraq
}

\section{${ }^{*}$ Corresponding author: \\ Basil Y. Mustafa, Department of Civil Engineering, Erbil \\ Technical Engineering College, Erbil Polytechnic University, Erbil, Kurdistan Region, Iraq E-mail: basil.mustafa@epu. edu.iq}

Received: 01 August 2019

Accepted: 10 September 2019

Published: 30 October 2019

\section{DOI}

10.25156/ptj.v9n2y2019.pp30-36

\section{A B S T R A C T}

The objective of this study is to identify the trend for the annual and monthly rainfall time series data from 1963-1964 to 2018-2019 for Erbil city rainfall gauging station. The trend analysis was conducted for only rainy months (from October to May) using the non-parametric Mann-Kendall test, whereas a non-parametric Sen's slope estimator was used to determine the magnitude of the trend. A functional relationship has been developed between variables using linear regression analysis to determine a linear trend of rainfall for the study area. The annual trend analysis revealed negative (decreasing) trend because the Kendall's tau $(Z)$ value and the Sen's slope estimator magnitude were both negative and found to be -0.093 and -1.37 , respectively, and the slope of the linear regression analysis was also negative and equal to $-0.9148 \mathrm{~mm} / \mathrm{year}$, which represents the rate of yearly annual rainfall decreasing trend. Considering the result of monthly rainfall, the trend analysis of rainfall has suggested that there is a trend variation of rainfall in the rainy months. Further, the analysis revealed a negative (decreasing) trend for months November, January, February, March, April, and May and positive (increasing) trend for months October and December. This study is important as it greatly contributes in water resources system planning and management in this region. Furthermore, the results obtained in this work are promising and might help hydraulic civil and water resource engineers in the design of hydraulic structures.

Keywords: Rainfall trend; Mann-Kendall Test; Sen's slope estimator; Regression analysis

\section{INTRODUCTION}

Rainfall is one of the vital climatic factors that can indicate climate change. Spatial and temporal changes of rainfall would influence runoff, soil moisture, and groundwater reserves. The analysis of rainfall trends is important in studying the impacts of climate change for water resources planning and management. Agriculture of Kurdistan region in the north of Iraq primarily depends on rainfall and its distribution. Distribution of rainfall is the major factor in the planning and management of projects related to water resources such as agricultural production, water requirement changes, irrigation, and reservoir operation (Corte-Real et al., 1998; Chakraborty et al., 2013). Different spatial and temporal scales of rainfall trend have been analyzed by many researchers in a variety of geophysical fields over the past century due to the warnings given by the scientific community about the global climate change, indicating a small positive global trend, even though large areas are instead characterized by negative trends (IPCC, 2007). Impact of climate change in the future is quite severe as given by IPCC reports which signify that there will be a reduction in the freshwater availability. This has also been revealed that by the middle of the $21^{\text {st }}$ century, a decrease in annual average runoff and availability of water will project up to $10-30 \%$ (IPCC, 2007).

Various researchers have contributed to the study of climate change (Dessens and Bucher, 1995; Serra et al., 2001; Marengo, 2004) with long-term data. The study of different time series data has proved that trend is either decreasing or increasing, both in case of temperature and rainfall. Human interference is also leading to climate change with changing the land use from the impact of agricultural and irrigation practices (Kalnay and Cai, 2003). Some researchers have also studied the availability of quality freshwater which is of the biggest concern for the last half-century, due to higher demographic pressure, leading to climatic variability (Gleick, 1993, 2000; Vörösmarty et al., 2000; Shiklomanov and Rodda, 2003; Milliman et al., 2008).

Analyzing the long-term series of data is used in this study for predicting the influence of climate changes. With the growing recognition of the possibility of the adverse impact of global climate change on water resources and the background of the previous researches, changes in 
rainfall have been studied to assess the spatial pattern of rainfall trends on monthly and annual scales over Erbil city in Kurdistan region, Iraq.

\section{MATERIALS AND METHODS}

\section{The Area Under Study}

The study area, Erbil city is located in Kurdistan region north of Iraq. Geographically, it is situated, as shown in Figure 1, at $36^{\circ} 12^{\prime} \mathrm{N}$ latitude and $44^{\circ} 02^{\prime}$ E longitudes and it is a part of Erbil Governorate. The area falls in semi-arid zone, with hot summers and cold winter, the average annual temperature varies from $4^{\circ} \mathrm{C}$ to $42^{\circ} \mathrm{C}$. The rainfall occurs from October to May. Full and complete meteorological data records are available for the area from Erbil meteorological station. The average annual rainfall is around $400 \mathrm{~mm}$. The basin's economy mostly depends on agriculture, thus analyzing its rainfall trend is important.

\section{Data Collection}

Monthly and annual rainfall data of Erbil city for the period of 53 years from 1963-1964 to 2018-2019 have been collected from the Directorate of Irrigation, Erbil.

\section{Rainfall Analysis}

Trend analysis for hydrometeorological variables in terms of rainfall, mean temperature, relative humidity, wind speed, and streamflow has been of particular interest to hydrologists and researchers for several years. The previous studies suggested that the most widely used method is the non-parametric Mann-Kendall test. Trend study for rainfall of the study area implemented following three steps; first was to determine the trend whether increasing, decreasing, or no trend by applying the Mann-Kendall (non-parametric) test for both annual and monthly rainfall data series. In the second step, the magnitude of trend was estimated using the Sen's slope estimator. However, the third step was to develop regression models for the observed rainfall data series. The details of the steps for trend analysis are explained below:

\section{Mann-Kendal trend test analysis}

The use of the Mann-Kendall (MK) test (Mann, 1945; Kendall, 1975; Gilbert, 1987) is to statistically find weather if there is a monotonic upward or downward trend of the variable of interest overtime. An upward trend means that the variable consistently increases through time and vice versa. It is worth mentioning that the trend may take linear and non-linear forms. The MK test can be applied in place of parametric linear regression analysis if the gradient of the linear regression is other than zero. The regression analysis requires that the residuals from the fitted regression line to be normally distributed. The MK test statistic $S$ is calculated using the formula that follows:

$$
S=\sum_{i=1}^{N-1} \sum_{j=i+1}^{N} \operatorname{sgn}\left(x_{j}-x_{i}\right)
$$

Where, $x_{j}$ and $x_{i}$ are monthly or annual rainfall values in months or years $j$ and $i, j>I$, respectively, and $\mathrm{N}$ is the number of data points. The value of $\operatorname{sgn}\left(x_{j}-x_{j}\right)$ is computed as follows:

$$
\operatorname{sgn}\left(x_{j}-x_{i}\right)= \begin{cases}1 & \text { if }\left(x_{j}-x_{i}\right)>0 \\ 0 & \text { if }\left(x_{j}-x_{i}\right)=0 \\ -1 & \text { if }\left(x_{j}-x_{i}\right)<0\end{cases}
$$

The above statistical equation represents the number of positive differences minus the number of negative differences for all the differences considered. If it is a positive number, observations obtained later in time tend to be larger than observations made earlier. If it is a negative number, then observations made later in time tend to be smaller than observations made earlier.

For large samples $(N>10)$, the test is conducted using a normal approximation ( $\mathrm{Z}$ statistics) with the mean and the variance as follows:

$$
E S=0
$$

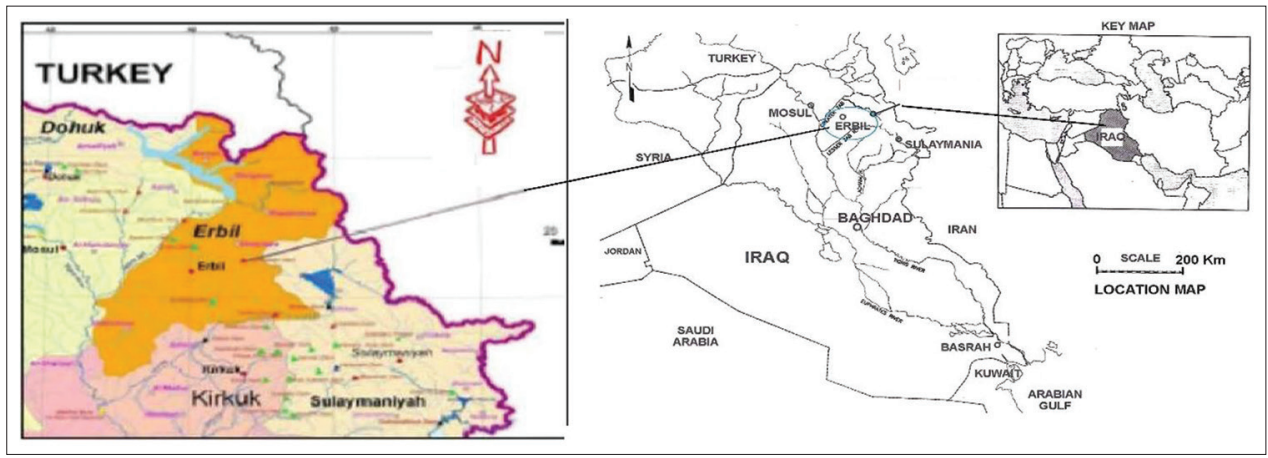

Figure 1: Location of the study area 
$\operatorname{Var}(S)=\frac{1}{18} N(N-1)(2 N+5)-\sum_{p=1}^{q} t_{p}\left(t_{p}-1\right)\left(2 t_{p}+5\right)(4)$

Here, $q$ is the number of tied (zero difference between compared values) groups and $t_{p}$ is the number of data values in the $\mathrm{p}^{\text {th }}$ group. The values of $\mathrm{S}$ and $\operatorname{VAR}(\mathrm{S})$ are used to compute the test statistic $Z$ as follows:

$$
Z= \begin{cases}\frac{S-1}{\sqrt{\operatorname{Var}(S)}} & \text { if } S>0 \\ 0 & \text { if } S=0 \\ \frac{S+1}{\sqrt{\operatorname{Var}(S)}} & \text { if } S<0\end{cases}
$$

The presence of a statistically significant trend is evaluated using the $Z$ value. A positive value of $Z$ indicates an upward (an increasing) trend and its negative value represents a downward (a decreasing) trend. The statistic $Z$ has a normal distribution. To test for either an upward or downward monotone trend (a two-tailed test) at $\alpha$ level of significance, $H_{0}$ is rejected if the absolute value of $Z$ is greater than $Z_{1}-\alpha / 2$, where $Z_{1}-\alpha / 2$ is obtained from the standard normal cumulative distribution tables (Richard, 1987). The $\mathrm{Z}$ values were tested at 0.05 level of significance.

\section{Sen's slope estimator calculation}

The magnitude of trend is predicted by Sen's estimator. To estimate the true slope of an existing trend, the Sen's non-parametric method is used. The Sen's method can be used in cases where the trend can be assumed to be linear (Sen, 1968).

$$
f(t)=Q_{t}+B
$$

Where, $\mathrm{Q}$ is the slope, $\mathrm{B}$ is a constant, and $t$ is time. To get the slope estimate $Q$, the slopes of all data value pairs are first calculated using the equation:

$$
Q=\frac{x_{j}-x_{k}}{j-k}
$$

Where, $x_{j}$ and $x_{k}$ are data values at time $j$ and $k(j>k)$, respectively. If there are $n$ values $x_{j}$ in the time series, there will be as many as $N=n(n-1) / 2$ slope estimates $Q_{i}$ The Sen's estimator of slope is the median of these $N$ values of $Q_{i}$. The $N$ values of $Q_{i}$ are ranked from the smallest to the largest and the Sen's estimator is $\mathrm{Q}=\mathrm{Q}_{\frac{(N+1)}{2}}$ if $N$ is odd or $\mathrm{Q}=\frac{1}{2}\left(\mathrm{Q}_{\frac{N}{2}}+\mathrm{Q}_{\frac{(N+1)}{2}}\right)$ if $N$ is even.

To obtain an estimate of $\mathrm{B}$ in Equation $\mathrm{f}(\mathrm{t})$, the $n$ values of differences $x_{i}-\mathrm{Q}_{\mathrm{ti}}$ are calculated. The median of these values gives an estimate of $\mathrm{B}$.

\section{Simple linear regression analysis}

Regression analysis is a statistical process for estimating the relationships among variables. It includes many techniques for modeling and analyzing several variables when the focus is on the relationship between a dependent variable and one or more independent variables. This is a parametric analysis which assumes normal distribution of time series data. The regression analysis is generally applied for testing a linear trend by developing inner relationship between time and the variable of interest. The precise use of this method needs the variables to be distributed normally and spatial and temporal independent. The regression analysis was performed on the observed rainfall time series data. In a specific station, trend in rainfall can be studied by variable and annual and monthly rainfall as the dependent variable. A simple linear regression model is in equation form of:

$$
Y=m X+C \ldots \ldots
$$

Where, $Y=$ rainfall, $X=$ time in months or years, $\mathrm{m}=$ slope coefficient $(\mathrm{mm} /$ year), and $\mathrm{c}=$ least square estimates of the intercept. The sign of the slope defines the direction of trend variable: Increasing if the sign is positive and decreasing if the sign is negative.

\section{RESULTS AND DISCUSSION}

The statistical analysis of the rainfall data is shown in Table 1. From the table, it can be seen that the mean annual rainfall of the study area over 53 years was found to be $395.98 \mathrm{~mm}$, the maximum and minimum annual rainfall were $767.90 \mathrm{~mm}$ and $177.3 \mathrm{~mm}$ in 2018-2019 and 20072008 , respectively. The maximum and minimum average monthly rainfalls over 53 years were found to be $70.82 \mathrm{~mm}$ and $14.11 \mathrm{~mm}$ in December and May, respectively.

The annual rainfall data trend analysis as well as monthly rainfall data (October-May) has been obtained by MK and Sen's slope estimator in this study for evaluating trend and magnitude for Erbil city using XLSTAT software. The regression analysis has also been used to develop a linear relationship between observed rainfall data with respect to time.

The annual trends of rainfall and their magnitude in $\mathrm{mm} /$ year obtained by the Mann-Kendall test, the Sen's slope estimator and the linear regression are given in Table 2. As per Table 2, the computed $P$-value using annual rainfall data is greater than the significance level alpha $=0.05$, one cannot reject the null hypothesis $\mathrm{H}_{0}$ which assumes that there is no trend exist so it means that annual rainfall observations obtained overtime are independent, identically distributed and there is no significant trend in annual rainfall over long term. 
Hussien, et al.

Table 1: Statistical properties of Erbil city rain gauge station annual and monthly rainfall series for 53 years

\begin{tabular}{|c|c|c|c|c|c|c|c|c|c|}
\hline Months & October & November & December & January & February & March & April & May & Annual \\
\hline 1963-1964 & 11.5 & 0.0 & 70.5 & 43.1 & 94.7 & 51.8 & 14.0 & 0.0 & 285.6 \\
\hline 1964-1965 & 0.0 & 12.5 & 34.6 & 104.1 & 70.5 & 42.0 & 74.7 & 10.0 & 348.4 \\
\hline 1965-1966 & 12.5 & 6.5 & 33.2 & 52.0 & 89.2 & 135.4 & 11.5 & 3.0 & 343.3 \\
\hline $1966-1967$ & 10.0 & 23.9 & 58.4 & 47.6 & 77.2 & 84.8 & 22.8 & 35.5 & 360.2 \\
\hline $1967-1968$ & 1.5 & 121.2 & 82.4 & 64.0 & 30.9 & 36.8 & 92.6 & 70.1 & 499.5 \\
\hline 1968-1969 & 20.3 & 60.4 & 161.3 & 135.5 & 33.2 & 176.5 & 111.7 & 16.6 & 715.5 \\
\hline 1969-1970 & 0.8 & 69.5 & 69.3 & 144.0 & 5.7 & 35.6 & 35.6 & 0.0 & 360.5 \\
\hline $1970-1971$ & 0.0 & 34.5 & 0.0 & 20.7 & 47.8 & 52.1 & 170.5 & 3.6 & 329.2 \\
\hline $1971-1972$ & 0.0 & 74.6 & 78.9 & 58.0 & 68.9 & 60.5 & 45.8 & 52.4 & 439.1 \\
\hline $1972-1973$ & 0.0 & 43.5 & 77.3 & 35.4 & 97.5 & 23.0 & 13.8 & 37.2 & 327.7 \\
\hline $1973-1974$ & 0.0 & 23.6 & 31.0 & 95.9 & 58.5 & 237.9 & 77.6 & 0.0 & 524.5 \\
\hline $1974-1975$ & 1.0 & 30.9 & 45.7 & 63.3 & 108.7 & 34.2 & 44.7 & 32.7 & 361.2 \\
\hline 1975-1976 & 1.0 & 21.0 & 111.6 & 77.3 & 96.2 & 125.6 & 59.1 & 38.4 & 530.2 \\
\hline $1976-1977$ & 20.5 & 4.8 & 30.4 & 0.0 & 63.9 & 29.0 & 81.8 & 8.2 & 238.6 \\
\hline 1977-1978 & 8.6 & 21.3 & 134.4 & 99.4 & 117.0 & 60.8 & 10.3 & 2.6 & 454.4 \\
\hline 1978-1979 & 0.2 & 21.8 & 0.0 & 90.0 & 71.1 & 43.9 & 5.2 & 12.8 & 245 \\
\hline 1979-1980 & 31.3 & 28.0 & 93.3 & 35.1 & 150.6 & 71.1 & 64.7 & 0.0 & 474.1 \\
\hline 1981-1982 & 24.0 & 67.3 & 50.5 & 124.5 & 38.7 & 33.5 & 111.9 & 24.7 & 475.1 \\
\hline 1982-1983 & 59.6 & 16.0 & 25.2 & 44.2 & 54.3 & 19.2 & 35.4 & 24.2 & 278.1 \\
\hline 1984-1985 & 0.0 & 0.0 & 43.9 & 80.0 & 146.7 & 84.3 & 40.4 & 0.0 & 395.3 \\
\hline 1985-1986 & 22.5 & 22.3 & 64.7 & 46.2 & 107.8 & 0.0 & 0.0 & 0.0 & 263.5 \\
\hline 1987-1988 & 15.3 & 29.1 & 181.8 & 177.3 & 106.0 & 112.9 & 56.6 & 0.0 & 679.0 \\
\hline 1988-1989 & 3.6 & 23.2 & 147.3 & 20.6 & 24.2 & 87.4 & 0.0 & 2.7 & 309.0 \\
\hline 1989-1990 & 3.1 & 167.5 & 61.8 & 86.4 & 113.4 & 9.3 & 48.9 & 5.3 & 495.7 \\
\hline 1990-1991 & 0.0 & 6.6 & 62.1 & 34.9 & 74.5 & 105.5 & 0.0 & 3.5 & 287.1 \\
\hline 1991-1992 & 12.6 & 41.3 & 71.8 & 141.0 & 128.7 & 45.4 & 31.8 & 48.9 & 521.5 \\
\hline 1992-1993 & 2.6 & 200.7 & 140.1 & 62.7 & 73.7 & 48.5 & 131.4 & 55.6 & 715.3 \\
\hline 1993-1994 & 19.4 & 16.4 & 77.0 & 52.2 & 95.6 & 106.4 & 55.5 & 19.6 & 442.1 \\
\hline 1994-1995 & 63.6 & 122.5 & 98.3 & 54.0 & 141.5 & 83.5 & 70.5 & 4.7 & 638.6 \\
\hline 1995-1996 & 11.6 & 53.2 & 13.8 & 116.2 & 22.6 & 113.7 & 45.7 & 4.5 & 381.3 \\
\hline 1996-1997 & 10.9 & 15.0 & 96.9 & 71.9 & 65.2 & 81.5 & 40.8 & 11.5 & 393.7 \\
\hline 1997-1998 & 25.1 & 52.0 & 90.7 & 112.3 & 46.3 & 82.5 & 44.7 & 12.4 & 466.0 \\
\hline 1998-1999 & 1.2 & 5.3 & 27.8 & 54.1 & 70.2 & 14.5 & 14.4 & 2.1 & 189.6 \\
\hline 1999-2000 & 8.8 & 12.2 & 54.2 & 51.5 & 18.8 & 21.4 & 14.5 & 8.0 & 189.4 \\
\hline 2000-2001 & 7.9 & 14.8 & 51.5 & 28.9 & 42.6 & 96.5 & 35.7 & 12.4 & 290.3 \\
\hline 2001-2002 & 4.4 & 19.6 & 85.0 & 89.0 & 21.4 & 115.5 & 71.4 & 2.4 & 408.7 \\
\hline 2002-2003 & 30.1 & 30.4 & 181.9 & 60.7 & 69.2 & 99.6 & 43.9 & 25.5 & 541.3 \\
\hline 2003-2004 & 15.9 & 81.0 & 100.3 & 116.0 & 93.3 & 6.4 & 82.3 & 1.3 & 496.5 \\
\hline 2004-2005 & 3.7 & 125.0 & 44.5 & 75.6 & 84.1 & 50.7 & 26.1 & 17.3 & 427.0 \\
\hline 2005-2006 & 9.0 & 15.3 & 19.4 & 84.9 & 189.0 & 15.3 & 77.9 & 21.8 & 432.6 \\
\hline 2006-2007 & 88.1 & 21.0 & 16.1 & 55.5 & 98.6 & 39.0 & 49.1 & 15.6 & 383.0 \\
\hline 2007-2008 & 0.0 & 5.4 & 8.9 & 42.4 & 52.7 & 61.4 & 4.6 & 1.9 & 177.3 \\
\hline 2008-2009 & 82.7 & 19.2 & 32.2 & 1.6 & 29.0 & 88.7 & 28.6 & 5.4 & 287.4 \\
\hline 2009-2010 & 36.6 & 16.3 & 105.4 & 34.9 & 74.3 & 71.0 & 32.2 & 25.6 & 396.3 \\
\hline 2010-2011 & 6.1 & 0.0 & 43.3 & 113.9 & 42.8 & 30.5 & 101.9 & 12.7 & 351.2 \\
\hline 2011-2012 & 10.6 & 7.4 & 25.0 & 56.1 & 31.5 & 60.4 & 9.6 & 11.7 & 212.3 \\
\hline 2012-2013 & 17.9 & 42.3 & 75.9 & 134.4 & 53.9 & 15.7 & 48.2 & 29.1 & 417.4 \\
\hline 2013-2014 & 0.0 & 21.6 & 84.1 & 60.9 & 7.0 & 83.3 & 9.5 & 1.7 & 268.1 \\
\hline 2014-2015 & 67.7 & 63.6 & 51.5 & 25.6 & 21.4 & 52.0 & 11.2 & 3.4 & 296.4 \\
\hline 2015-2016 & 31.9 & 79.1 & 104.9 & 35.0 & 23.7 & 89.9 & 36.6 & 6.7 & 407.8 \\
\hline 2016-2017 & 0.0 & 0.0 & 110.0 & 27.9 & 14.2 & 63.5 & 38.0 & 2.4 & 256.0 \\
\hline 2017-2018 & 0.0 & 18.4 & 18.7 & 29.7 & 138.5 & 7.0 & 0.0 & 0.0 & 212.3 \\
\hline 2018-2019 & 30.2 & 122.0 & 174.7 & 101.9 & 49.7 & 191.8 & 97.6 & 0.0 & 767.9 \\
\hline Mean & 15.96 & 40.58 & 70.82 & 69.25 & 70.69 & 67.71 & 46.85 & 14.11 & 395.98 \\
\hline SD & 21.25 & 43.82 & 46.26 & 39.15 & 41.34 & 47.98 & 37.00 & 16.51 & 143.75 \\
\hline Skew & 1.98 & 1.86 & 0.75 & 0.62 & 0.60 & 1.29 & 1.05 & 1.55 & 0.76 \\
\hline Median & 9.00 & 22.30 & 64.70 & 60.70 & 69.20 & 60.50 & 40.80 & 8.00 & 383.00 \\
\hline
\end{tabular}


The annual trend analysis revealed negative (decreasing) trend because both the Kendall's tau $(Z)$ value and Sen's slope estimator magnitude were negative and found to be -0.093 and -1.37 , respectively. The regression analysis was performed for the annual rainfall time series data, as shown in Figure 2, and the slope of the linear regression analysis was negative and equal to $-0.9148 \mathrm{~mm} /$ year which represents the yearly annual rainfall decreasing trend rate which is almost similar to the rainfall trends found by the Mann-Kendall test and the Sen's slope estimator as indicated a negative (decreasing) trend.

The non-parametric MK test was also applied to detect the trend of average monthly rainfall for 53 years from October to May for each rainy month individually, along with the Sen's magnitude and the linear regression slope (m) has been calculated. The results are shown in Table 3 and Figure 3.

Table 2: Annual rainfall trend results for Mann-Kendall test, Sen's slope estimator, and regression analysis

\begin{tabular}{lc}
\hline Statistical parameters & Calculated values \\
\hline Kendall's tau & -0.093 \\
$\mathrm{~S}$ & -128.000 \\
Var. (S) & 16995.333 \\
p-value (two tailed) & 0.326 \\
Alpha & 0.05 \\
Sen's slope & -1.370 \\
Slope of linear regression analysis $(\mathrm{m})$ & -0.8094 \\
\hline
\end{tabular}

As it is shown from Table 3, the computed p-value for all months' rainfall data is greater than the significance level alpha $=0.05$, one cannot reject the null hypothesis $\mathrm{H}_{\mathrm{o}}$ which assumes that there are no trend exists. There are a negative (decreasing) trend for months November, January, February, March, April, and May because the Kendall's tau $(Z)$ and the Sen's slope values were both negative, whereas the Kendall's tau $(Z)$ and the Sen's slope values indicated a positive trend for months October and December. This result is quite significant as the months where the MK trend analysis has shown a negative trend, the similar negative slope has been observed for the Sen's slope and vice versa.

The regression analysis was performed for the monthly rainfall time series data, as shown in Figure 3, and the slope of the linear regression analysis was negative for months November, January, February, March, April, and May and found to be $-0.0612,-0.252,-4141,-0.2138$, -0.3904 , and $-0.2441 \mathrm{~mm} /$ year, respectively. This slope also represents the monthly rainfall decreasing trend rate per year, whereas the slope values were positive for months October and December and were equal to 0.3743 and $0.1642 \mathrm{~mm} /$ year, respectively. This slope represents the monthly rainfall increasing trend rate per year. The linear regression trend test result was almost similar to the monthly rainfall trends found by the MK test and the Sen's slope estimator.

Table 3: Monthly rainfall trend results for Mann-Kendall test, Sen's slope estimator, and regression analysis

\begin{tabular}{|c|c|c|c|c|c|c|c|c|}
\hline \multirow{2}{*}{$\begin{array}{l}\text { Statistical parameters } \\
\text { Months }\end{array}$} & \multicolumn{8}{|c|}{ Calculated values } \\
\hline & October & November & December & January & February & March & April & May \\
\hline Kendall's tau & 0.179 & -0.044 & 0.026 & -0.086 & -0.163 & -0.028 & -0.105 & -0.091 \\
\hline S & 242.000 & -61.000 & 36.000 & -119.000 & -225.000 & -38.000 & -144.000 & -124.000 \\
\hline Var. (S) & 16829.333 & 16985.667 & 16993.333 & 16994.333 & 16994.333 & 16995.333 & 16990.667 & 16901.333 \\
\hline $\mathrm{p}$-value (two tailed) & 0.062 & 0.64 & 0.782 & 0.361 & 0.084 & 0.771 & 0.269 & 0.340 \\
\hline Alpha & 0.05 & 0.05 & 0.05 & 0.05 & 0.05 & 0.05 & 0.05 & 0.05 \\
\hline Sen's slope & 0.152 & -0.071 & 0.164 & -0.253 & -0.562 & -0.112 & -0.294 & -0.058 \\
\hline $\begin{array}{l}\text { Slope of linear } \\
\text { regression analysis }(m)\end{array}$ & 0.3743 & -0.0612 & 0.1642 & -0.252 & -4141 & -0.2138 & -0.3904 & -0.2441 \\
\hline
\end{tabular}

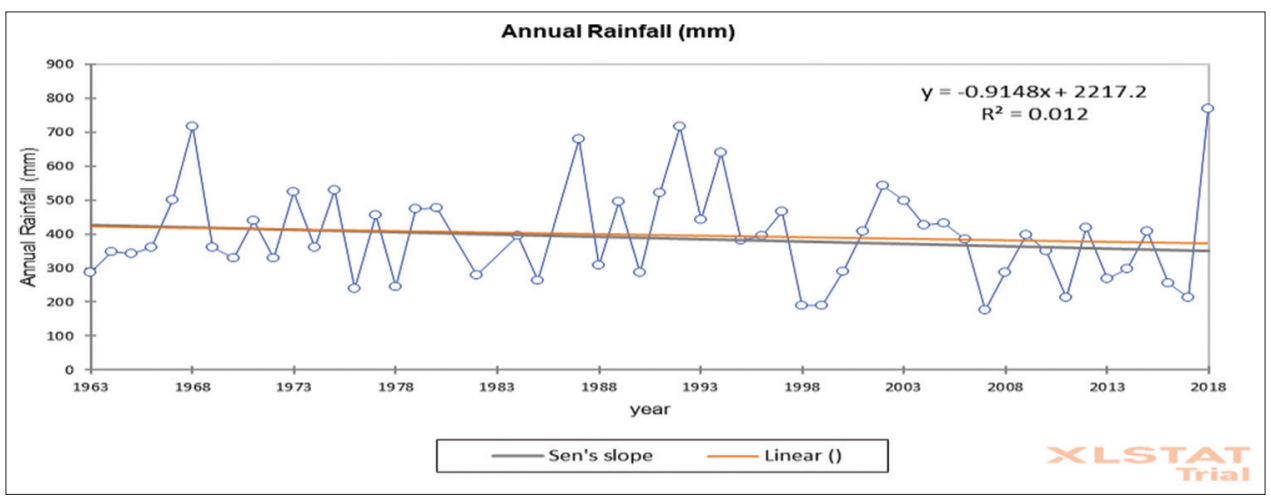

Figure 2: Annual rainfall variation of the study area duration from 1963-1964 to 2018-2019 


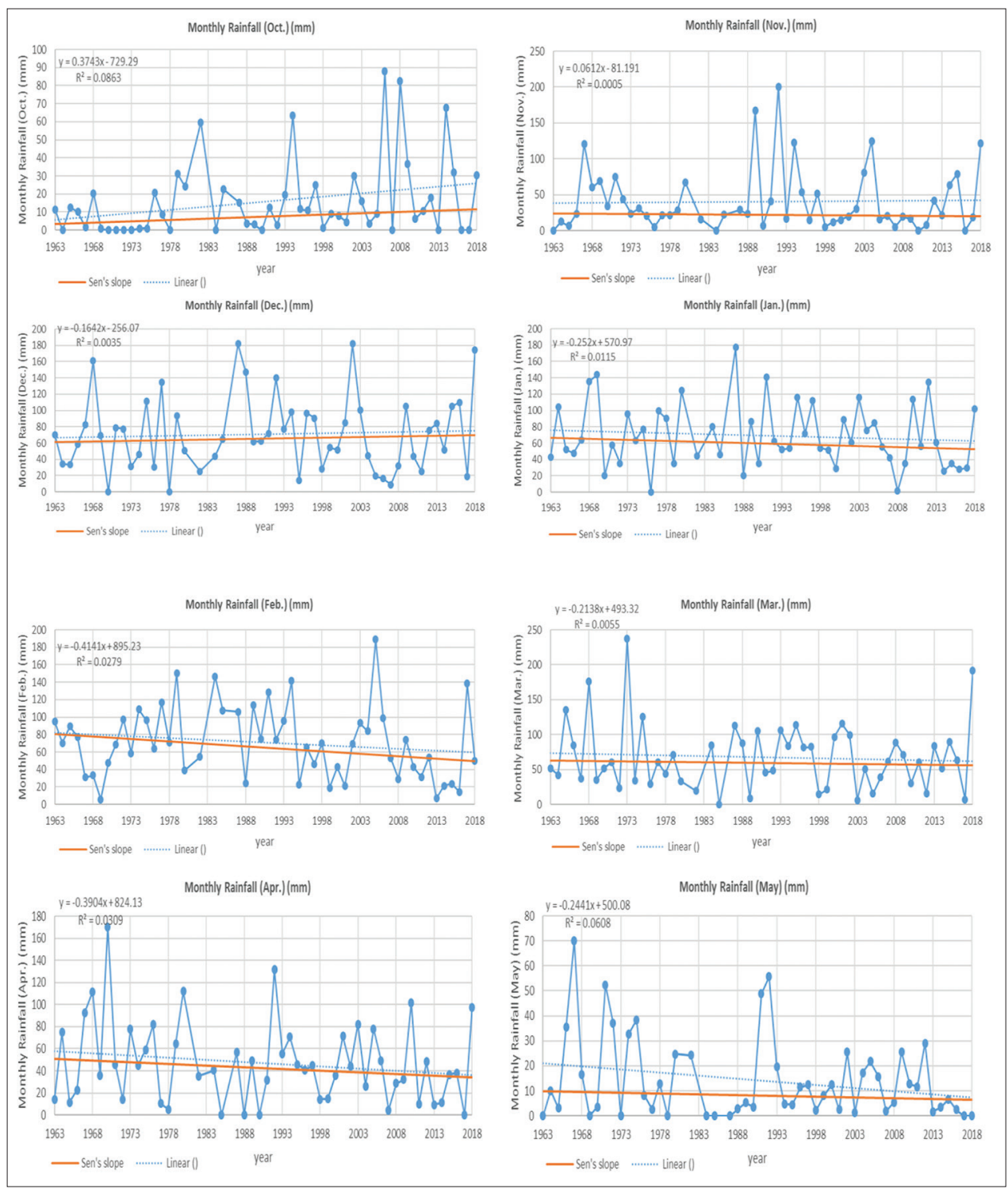

Figure 3: Average monthly rainfall variation for 53 years from October to May for the study area

\section{CONCLUSIONS}

In this paper, the annual and monthly trends of rainfall were investigated in Erbil city rainfall gauging station by nonparametric MK test, and the Sen's slope estimator and by parametric linear regression test. For this purpose, records from Erbil rain gauge station over 53 years from 1963-1964 to 2018-2019 were analyzed. The results indicated that (negative) decreasing trend in annual rainfall found with significant trends observed at the $95 \%$ confidence levels. The yearly annual rainfall decreasing trend rate was equal to $-0.9148 \mathrm{~mm} /$ year. The monthly rainfall trend analysis results revealed decreasing (negative) trend for months November, January, February, March, April, and May, whereas Kendall's test indicated increasing (positive) trend for months October and December. The parametric (linear regression) trend analysis showed the same trend results, the monthly rainfall decreasing trend rate was equal to -0.0612 , $-0.252,-4141,-0.2138,-0.3904$, and $-0.2441 \mathrm{~mm} /$ year for months November, January, February, March, April, and May, respectively, and the monthly rainfall increasing trend rate was equal to 0.3743 and $0.1642 \mathrm{~mm} /$ year for months October and December, respectively. The results obtained in this work are promising and might help hydraulic civil and water resource engineers in the design of hydraulic structures.

\section{ACKNOWLEDGMENTS}

The authors are thankful to "Directorate of Irrigation, Erbil," for providing data for this study. We are also grateful to all those individuals whose suggestions have helped to improve the quality of this article. 


\section{REFERENCES}

Corte-Real, J., B. Qian and H. Xu. 1998. Regional climate change in Portugal: Precipitation variability associated with large-scale atmospheric circulation. Int. J. Climat. 18(6): 619-635.

Chakraborty, S., R. P. Pandey, U. P. Chaube and S. K. Mishra. 2013. Trend and variability analysis of rainfall series at Seonath River Basin, Chhattisgarh (India). Int. J. Appl. Sci. Eng. Res. 2(4): 425-434.

Dessens, J. and A. Bucher. 1995. Changes in minimum and maximum temperatures at the Pic du Midi relation with humidity and cloudiness, 1882-1984. Atmos. Res. 37: 147-162.

Gleick, P. H. 1993. Water in Crisis: A Guide to the World's Fresh Water Resources. Oxford University Press, p504.

IPCC. 2007. Climate Change 2007: Climate Change Impacts, Adaptation and Vulnerability. Working Group II Contribution to the Intergovernmental Panel on Climate Change $4^{\text {th }}$ Assessment Report. Summary for Policymakers. p23.

IPCC. 1996. Climate change. In: Houghton, J. T., L. G. M. Filho, B. A. Callander, N. Harris, A. Kattenberg and K. Maskell., editors. The IPCC Second Assessment Report. Cambridge University Press, New York.

Jayewardene, H. K. W., D. U. J. Sonnadara and D. R. Jayewardene. 2005. Trends of rainfall in Sri Lanka over the last century. Sri Lankan J. Phys. 6: 7-17.

Kalnay, E. and M. Cai. 2003. Impact of urbanization and land-use change on climate. Nature. 423: 528-531.

Kendall, M. G. 1975. Rank Correlation Methods. Charles Griffin, London, UK.

Kumar, V., S. K. Jain. and Y. Singh. 2010. Analysis of long-term rainfall trends in India. Hydrol. Sci. J. 55(4): 484-496.

Thenmozhi, M. and S. V. Kottiswaran. 2016. Analysis of rainfall trend using Mann-Kendall test and the Sen's slope estimator in Udumapet of Tirupur district in Tamil Nadu. Int. J. Agric. Sci. Res. 6(2): 131-138.

Mani, K. V., M. K. Verma and S. Swain. 2016. Statistical analysis of precipitation over Seonath river basin, Chhattisgarh, India. Int. J. Appl. Eng. Res. 11(4): 2417-2423.
Mann, H. B. 1945. Nonparametric tests against trend. Econometrical. 13: $245-259$.

Marengo, J. A. 2004. Inter-decadal variability and trends of rainfall across the Amazon basin. Theor. Appl. Climatol. 78: 79-96.

Milliman, J. D., K. L. Farnsworth, P. D. Jones, K. H. Xu and L. C. Smith. 2008. Climatic and anthropogenic factors affecting river discharge to the global ocean, 1951-2000. Glob. Planet. Change. 62 (3-4): 187-194.

Olofintoye, O. and J. Adeyemo. 2011. The role of global warming in the reservoir storage drop at Kainji dam in Nigeria. Int. J. Phys. Sci. 6(19): 4614-4620.

Parta, T. and E. Kahya. 2006. Trend analysis in Turkish precipitation data. Hydrol. Processes. 20: 2011-2026.

Richard, O. G. 1987. Statistical Methods for Environmental Pollution Monitoring. Van Nostrand Reinhold Company Inc., New York.

Salmi, T., A. Määttä, P. Anttila, T. Ruoho-Airola and T. Amnell. 2002. Detecting Trends of Annual Values of Atmospheric Pollutants by the Mann-Kendall Test and Sen's Slope Estimates-the Excel Template Application Makesens. Vol. 31. Finnish Meteorol, Institute Publication on Air Quality, Helsinki. p1-35.

Sen, P. K. 1968. Estimates of the regression coefficient based on Kendall's Tau. J. Am. Stat. Assoc. 63: 1379-1389.

Serra, C., A. Burgueno and X. Lana. 2001. Analysis of maximum and minimum daily temperatures recorded at fabra observatory (Barcelona, NE Spain) in the period 1917-1998. Int. J. Climatol. 21: 617-636.

Shiklomanov, I. A. and J. C. Rodda. 2003. World Water Resources at the Beginning of the $21^{\text {st }}$ Century. International Hydrology Series. Cambridge University Press, Cambridge. p435.

Sourabh, N., M. K. Awasthi and R. K. Nema. 2016. Trend analysis of annual and seasonal rainfall in Tawa command Area. Int. J. Environ. Agric. Biotechnol. 1(4): 952-957.

Vörösmarty, C. J., P. Green, J. Salisbury and R. B. Lammers. 2000. Global water resources: Vulnerability from climate changes and population growth. Science. 289: 284-288. 